\title{
Relationship between 17-alpha hydroxyprogesterone caproate concentration and spontaneous preterm birth
}

\author{
Steve N. CARITIS, MD1, Raman VENKATARAMANAN, PhD², Elizabeth THOM, PhD ${ }^{3}$, \\ Margaret HARPER, MD ${ }^{4}$, Mark A. KLEBANOFF, MD ${ }^{5}$, Yoram SOROKIN, MD ${ }^{6}$, John M. \\ THORP Jr., MD ${ }^{7}$, Michael W. VARNER, MD $^{8}$, Ronald J WAPNER, MD $^{9}$, Jay D. IAMS, MD ${ }^{10}$, \\ Marshall W. CARPENTER, MD ${ }^{11}$, William A. Grobman, MD. MBA ${ }^{12}$, Brian M. MERCER, \\ MD $^{13}$, Anthony SCISCIONE, DO ${ }^{14}$, Dwight J. ROUSE, MD ${ }^{15}$, and Susan RAMIN, MD ${ }^{16}$ for the \\ Eunice Kennedy Shriver National Institute of Child Health and Human Development \\ Maternal-Fetal Medicine Units Network and Obstetrical-Fetal Pharmacology Research \\ Units Network \\ ${ }^{1}$ Department of Obstetrics and Gynecology and Reproductive Sciences and Pharmaceutical \\ Sciences University of Pittsburgh School of Medicine, Pittsburgh, PA \\ ${ }^{2}$ Department of Obstetrics and Gynecology and Reproductive Sciences and Pharmaceutical \\ Sciences University of Pittsburgh School of Pharmacy, Pittsburgh, PA \\ ${ }^{3}$ The George Washington University Biostatistics Center, Washington, DC \\ ${ }^{4}$ Departments of Obstetrics and Gynecology of Wake Forest University Health Sciences, \\ Winston-Salem, N.C. \\ ${ }^{5}$ Eunice Kennedy Shriver National Institute of Child Health and Human Development Maternal- \\ Fetal Medicine Units \\ ${ }^{6}$ Wayne State University, Detroit, MI \\ 7University of North Carolina at Chapel Hill, Chapel Hill, N.C. \\ ${ }^{8}$ University of Utah Health Sciences Center, Salt Lake City, UT \\ ${ }^{9}$ Columbia University, New York, NY \\ ${ }^{10}$ The Ohio State University, Columbus, $\mathrm{OH}$ \\ ${ }^{11}$ Women and Infants Hospital, Brown University, Providence, RI \\ ${ }^{12}$ Northwestern University, Chicago, IL \\ ${ }^{13}$ Case Western Reserve University-MetroHealth Medical Center, Cleveland, $\mathrm{OH}$ \\ ${ }^{14}$ Drexel University College of Medicine, Philadelphia, PA \\ ${ }^{15}$ University of Alabama at Birmingham, Birmingham, AL
}

\footnotetext{
(C) 2013 Mosby, Inc. All rights reserved.

Corresponding Author: Steve N. Caritis, MD 300 Halket Street; Room 2229 Pittsburgh, PA 15213 Phone: 412-641-4874 Fax: 412-641-1133 scaritis@mail.magee.edu.

Publisher's Disclaimer: This is a PDF file of an unedited manuscript that has been accepted for publication. As a service to our customers we are providing this early version of the manuscript. The manuscript will undergo copyediting, typesetting, and review of the resulting proof before it is published in its final citable form. Please note that during the production process errors may be discovered which could affect the content, and all legal disclaimers that apply to the journal pertain.

The authors report no conflict of interest

Parent trial originally presented at the Annual Scientific Meeting of the Society for Maternal-Fetal Medicine, January 31, 2008, Dallas, Texas.
} 
${ }^{16}$ University of Texas Health Science Center at Houston, Houston, TX

\section{Abstract}

Objective-17-alpha hydroxyprogesterone caproate (17-OHPC) $250 \mathrm{mg}$ weekly reduces recurrent spontaneous preterm birth (SPTB) in women with a prior SPTB by 33\%. The dose is not based on pharmacological considerations. A therapeutic concentration has not been determined hampering any attempt to optimize treatment. This study evaluated the relationship between 17OHPC plasma concentrations and the rate of SPTB in women with singleton gestation.

Study Design-A single blood sample was obtained between 25 and 28 weeks gestation from 315 women with a SPTB who participated in a placebo-controlled, prospective, randomized clinical trial evaluating the benefit of omega-3 supplementation in reducing preterm birth. All women in the parent study received 17-OHPC and 434 received omega-3 supplementation and 418 received a placebo. Plasma from 315 consenting women was analyzed for 17-OHPC concentration.

Results-There were no differences between placebo and omega-3 supplemented groups in demographic variables, outcomes or in mean 17-OHPC concentration. Plasma concentrations of 17-OHPC ranged from 3.7- $56 \mathrm{ng} / \mathrm{ml}$. Women with plasma concentrations of 17-OHPC in the lowest quartile had a significantly higher risk of spontaneous preterm birth $(\mathrm{p}=0.03)$ and delivered at significantly earlier gestational ages $(\mathrm{p}=0.002)$ than did women in the $2^{\text {nd }}$ to $4^{\text {th }}$ quartiles. The lowest preterm birth rates were seen when median 17-OHPC concentrations exceeded $6.4 \mathrm{ng} / \mathrm{ml}$.

Conclusions-Low plasma 17-OHPC concentration is associated with an increased risk of SPTB. This finding validates efficacy of this treatment but suggests that additional studies are needed to determine the optimal dosage.

\section{Keywords}

dose response; 17 hydroxyprogesterone caproate concentration-response; pharmacodynamics

\section{Introduction}

17-hydroxyprogesterone caproate (17-OHPC) reduces recurrent spontaneous preterm birth (SPTB) in women with a singleton gestation and a prior SPTB ${ }^{1}$. The American College of Obstetricians and Gynecologists endorses the use of 17-OHPC in women with a prior SPTB but notes that more research is required as to the optimal formulation and dosage ${ }^{2}$.

Fundamental to any pharmaceutical intervention is the establishment of an appropriate dose that has been determined in dose ranging studies that compare efficacy and harms over a range of doses ${ }^{3,4}$. There are no data providing guidance on the optimal dose of 17-OHPC. The dose utilized in the Maternal-Fetal Medicine Network (MFMU) trial reported by Meis et $\mathrm{al}^{1}$ was $250 \mathrm{mg}$ weekly given as an intramuscular (IM) injection. This dose was chosen based on the dosage used in previous studies and a meta-analysis ${ }^{5-8}$. In the MFMU trial a $33 \%$ reduction in recurrent SPTB rates was seen in women receiving weekly injections of $250 \mathrm{mg}$ 17-OHPC compared with those receiving placebo. Whether a higher dose would have provided greater benefit or even harm is not known.

The outcome of interest for 17-OHPC against which various doses can be evaluated, is SPTB but dose ranging studies are difficult to complete given the large sample size that would be needed. An alternative approach is to relate plasma drug concentration to the frequency of preterm birth to assess if a concentration - outcome relationship exists ${ }^{9-12}$. The purpose of this study was to evaluate the relationship between 17-OHPC concentration and gestational length in women with singleton gestation. 


\section{Materials and Methods}

This study utilized blood samples obtained from women who participated in the Omega-3 Maternal-Fetal Medicine Units Network (MFMU) trial that evaluated whether omega-3 supplementation reduced the rate of recurrent SPTB in women with a singleton gestation and a prior SPTB. All women received weekly intramuscular (IM) injections of $250 \mathrm{mg} 17$ OHPC starting between 16 0/7 -21 6/7 weeks and continuing until delivery or 36 6/7 weeks. In addition, subjects were randomly assigned to receive a daily supplement containing 1,200 $\mathrm{mg}$ of eicosapentaenoic acid (EPA, 20:5n-3) and $800 \mathrm{mg}$ of docosahexaenoic acid (DHA, 22:6n-3), for a total of 2,000 mg of omega-3 long-chain polyunsaturated fatty acids, divided into four capsules, or they received matching placebo capsules that contained only a minute amount of inert mineral oil. A blood sample was obtained between 25-28 weeks gestation just prior to the next scheduled dose of 17-OHPC and analyzed for the plasma concentration of 17-OHPC using high performance liquid chromatography- mass spectrometry with a limit of detection of $1 \mathrm{ng} / \mathrm{ml}^{13}$.

\section{Statistical Analysis}

The analysis was restricted to women who completed all their scheduled 17-OHPC injections. Demographic data were compared between the two treatment groups using chisquare or the Wilcoxon test as appropriate. A logistic regression with an interaction term was conducted to determine whether there was an interaction between 17-OHPC concentration and treatment group with respect to the outcome of preterm birth. Survival curve analysis with indicated and term births censored was performed to compare length of gestation between women in the first and other three quartiles. A proportional hazards model was performed with adjustment for gestational age at study entrance, gestational age at blood sampling, race, ethnicity and body mass index (BMI) to assess the relationship between 17-OHPC plasma concentrations and gestational age at delivery. A nominal p-value $<0.05$ was considered significant with no adjustments for multiple comparisons. All tests were two-sided.

\section{Results}

Among the 852 women enrolled in the trial, 434 were randomized to receive omega-3 supplements and 418 were randomized to receive placebo. Blood samples were available on 512 subjects: 261 women in the omega-3 group and 251 in the placebo group. Among these women 162 in the omega-3 group and 153 in the placebo group received all of their scheduled 17-OHPC injections throughout the study and form the study population for this analysis. These women had received a median of 9 injections at the time of blood sampling which occurred at a mean gestational age of 27 weeks.

Table 1 summarizes the demographic and clinical characteristics of the study cohort stratified by omega-3 group assignment. There were no differences between the two groups in any of the parameters listed in the table. Mean plasma 17-OHPC concentrations were similar in the two treatment groups as were BMI and progesterone concentrations. A wide variation in plasma 17-OHPC concentrations was seen in both treatment groups with concentrations ranging from $3.7 \mathrm{ng} / \mathrm{ml}$ to $56 \mathrm{ng} / \mathrm{ml}$ in the entire cohort.

Because there were no differences in plasma 17-OHPC or progesterone concentrations and no interaction effect between 17-OHPC concentration and treatment group $(\mathrm{p}=0.52)$, we combined the two treatment groups for further analyses. Due to the large variation in 17OHPC concentrations, we stratified the concentration data by quartiles (Table 2). The SPTB rate was significantly $(p<0.03)$ greater among women in the first quartile compared with those in the other quartiles. Also, as demonstrated in the Kaplan-Meier curve of Figure 1, 
women in the first quartile of 17-OHPC concentration delivered significantly earlier than those in other quartiles $(\mathrm{p}=0.002)$. In a proportional hazards model, after controlling for the gestational age when the subject started treatment with 17-OHPC, the gestational age at blood sampling, treatment group assignment, BMI, race and ethnicity, those women in the combined second to fourth quartiles showed a 50\% reduction in the hazard of delivering preterm (hazard ratio $=0.48,95 \%$ confidence limits $0.31-0.75, \mathrm{p}=0.001$ ) compared with those women with plasma 17-OHPC concentrations in the first quartile.

To assess the relationship between concentration of 17-OHPC and SPTB rates, we compared the median 17-OHPC concentration in each quartile with the SPTB rate for each quartile in Figure 2. The SPTB rate was highest among women in the first quartile with median plasma $17-\mathrm{OHPC}$ concentrations of $6.4 \mathrm{ng} / \mathrm{ml}$.

\section{Comment}

We have demonstrated a significant relationship between the concentration of 17-OHPC and the rate of recurrent SPTB; rates were lower among women with higher concentrations of 17-OHPC. This observation has several important implications related to 17-OHPC specifically and progestin supplementation in general. First, the inverse relationship between 17-OHPC concentration and SPTB rates in this cohort of women indicates that 17-OHPC effectively reduced SPTB rates in some women regardless of omega 3 supplementation. Efficacy of 17-OHPC in this cohort could otherwise not be assessed since all women received 17-OHPC. The parent trial was not intended to evaluate the efficacy of 17-OHPC but rather the efficacy of omega-3 supplementation.

Secondly, the findings in this trial support the conclusions of the MFMU Network study reported by Meis et $\mathrm{al}^{1}$ that 17 -OHPC treatment reduces the rate of preterm birth. Blood samples were not obtained in that study, preventing any estimate of therapeutic concentration or any description of a drug concentration- outcome relationship.

Thirdly, in the study reported by Meis et $\mathrm{al}^{1}$, the rate of SPTB before 37 weeks in women treated with 17-OHPC was reduced by $33 \%$. The findings reported in the current study suggest that the effectiveness of 17-OHPC in reducing preterm birth rates may be influenced by the plasma concentration. Whether rates of preterm birth in women with a prior preterm birth can be improved by administering doses that provide higher concentrations of 17OHPC remains to be tested. All women received a dose of $250 \mathrm{mg}$ weekly but plasma concentrations varied substantially. Similar variation in 17-OHPC concentration has been reported in women with singleton or twin gestation ${ }^{14,15}$. This variation is at least in part attributable to differences in BMI but we have also demonstrated that endogenous pregnancy-related hormones can affect plasma 17-OHPC concentration ${ }^{16}$. Additional variation in plasma 17-OHPC concentration may be seen with certain medications that compete with the cytochrome P450 enzyme CYP3A4 which is a primary metabolic pathway for 17-OHPC and several commonly used medications ${ }^{17}$.

For most pharmaceuticals the proper dose is established by measuring clinical endpoints over a range of doses. Such studies have not been performed with 17-OHPC. The currently recommended dose of 17-OHPC of $250 \mathrm{mg}$ weekly was empirically chosen based on literature that was not informed by pharmacological data defining a proper dose or a therapeutic concentration ${ }^{5-8}$. Ideally, the optimal dosage of 17-OHPC should be determined by dose ranging studies. However, because a very large sample size is required when preterm birth is the endpoint, we have relied on assessing the relationship between plasma concentrations and the incidence of preterm birth. This study design is not optimal in that a single dose was administered and the range of plasma concentrations achieved was narrower 
than what could be expected from a study with a wider drug concentration range.

Specifically, such information could define a therapeutic range as well as a concentration above which no therapeutic benefit is seen or where harms may be seen. Our data suggest that clinical benefit may be improved in some women with higher plasma concentrations. Our data are not informative about benefits or harms related to higher concentrations of 17OHPC.

We used median 17-OHPC concentrations from each quartile of 17-OHPC concentrations to develop the concentration-response relationship, a statistical approach that is not as stringent as a dose ranging study. Nevertheless, this approach provides information that has heretofore not been available for singleton gestations. Our results require validation in other cohorts of women treated with 17-OHPC. We do not believe dosage adjustments of 17OHPC should be based on this single secondary analysis.

This and other reports from the MFMU indicate that 17-OHPC supplementation may have different effects on different populations of at risk women. For example, higher concentrations of 17-OHPC in twin gestations are associated with a shortened gestational length, an association opposite to that seen in singleton gestations ${ }^{12}$. Thus, increasing the dose of 17-OHPC in women with twin gestation would not be predicted to improve outcome. Indeed, in a study of women with twins and a short cervix, a dose of 500mg IM twice weekly led to an increase in risk of preterm birth when compared to women receiving no $17-\mathrm{OHPC}^{18}$. On the other hand it is not clear whether higher doses of 17-OHPC would improve outcomes in women who receive 17-OHPC for the indication of short cervix. In the only trial of 17-OPHC treatment of low risk asymptomatic women with a short cervix, Grobman et al reported that 17-OHPC did not reduce preterm birth rates among women with a singleton gestation and a cervical length less than the $10^{\text {th }}$ percentile $(<30 \mathrm{~mm})^{19}$.

Durnwald et al reported that a dose of $250 \mathrm{mg}$ weekly 17-OHPC did not affect the rate of cervical change in women with a prior preterm birth ${ }^{20}$. However, Facchinetti reported a reduction in the rate of cervical shortening in women with treated preterm labor receiving $341 \mathrm{mg}$ twice weekly 17-OHPC ${ }^{21}$. The dose used by Facchinetti was 2.5 times the standard dose used in the United States. Whether the lack of benefit from 17-OHPC in Grobman's study is due to an inadequate dose is unknown. Likewise it is not known, if in that cohort of subjects, a concentration-response relationship exists between 17-OHPC concentration and preterm birth rates.

Our findings have significance for progesterone supplementation in general. The mechanism of action of vaginal progesterone or 17-OHPC in reducing preterm birth rates is not known nor is the target tissue. The demonstration of a 17-OHPC concentration relationship to the outcome of preterm birth provides support for the concept that progesterone supplementation can reduce preterm birth rates despite high plasma progesterone concentrations in pregnancy that exceed the concentration required to half saturate the progesterone receptor.

In summary, we have demonstrated a relationship between 17-OHPC concentration and the outcome of spontaneous preterm birth in women with singleton gestation and a prior preterm birth. Further study is required to fully characterize this relationship. We do not recommend changing the current dose of 17-OHPC without additional studies to fully characterize the concentration or dose relationship between 17-OHPC and the rate of recurrent SPTB.

\section{Acknowledgments}

In addition to the authors, other members of the Eunice Kennedy Shriver National Institute of Child Health and Human Development Maternal-Fetal Medicine Units Network are as follows: 
University of Pittsburgh, Pittsburgh, PA - H. Simhan, M. Luce, M. Cotroneo

Wake Forest University Health Sciences, Winston-Salem, NC - P. Meis, M. Swain, B. Scott, C. Leftwich

Wayne State University, Detroit, MI - G. Norman, D. Driscoll, C. Sudz, L. Wynn, S. Blackwell

University of North Carolina at Chapel Hill, Chapel Hill, NC - K. Dorman, E. Prata, K. Hamden

University of Utah Health Sciences Center, Salt Lake City, UT - K. Anderson (University of Utah Health Sciences Center), S. Bonnemort (McKay-Dee Hospital), D. Lund (University of Utah Health Sciences Center), J. Russell (LDS Hospital), J. Parsons (Utah Valley Regional Medical Center)

Columbia University, New York, NY - S. Bousleiman, S. South, V. Carmona, H. Husami, C. Lankford, C. Perez

The Ohio State University, Columbus, $\mathrm{OH}$ - F. Johnson, M. Landon, D. Cline, H. Walker

Women and Infants Hospital, Brown University, Providence, RI - D. Allard, J. Tillinghast

Northwestern University, Chicago, IL - A. Peaceman, M. Dinsmoor (NorthShore University HealthSystem), P.J. Simon, M. Huntley, C. Whitaker-Carr, M. Ramos-Brinson, G. Mallett

Case Western Reserve University-MetroHealth Medical Center, Cleveland, OH - C. Milluzzi, J. Hunter, W. Dalton, H. Ehrenberg, B. Stetzer

Drexel University College of Medicine - M. Hoffman, M. Talucci, C. Tocci, S. Wilson, M. Lake

University of Alabama at Birmingham, Birmingham, AL - W.W. Andrews, A. Northen, M. Parks, P. Blake Files

The University of Texas Health Science Center at Houston, Houston, TX - L.C. Gilstrap, B. Glenn-Cole, K.

Cannon

The George Washington University Biostatistics Center - J. Zachary, R. Palugod, L. Leuchtenburg

Eunice Kennedy Shriver National Institute of Child Health and Human Development, Bethesda, MD - C. Spong, S. Tolivaisa

MFMU Network Steering Committee Chair (University of Texas Medical Center, Galveston, TX) — G. Anderson, M.D.

The project described was supported by grants from the Eunice Kennedy Shriver National Institute of Child Health and Human Development (NICHD) [HD047905, HD27860, HD27917, HD40560, HD34208, HD40485, HD21410, HD27915, HD40500, HD40512, HD40544, MO1-RR-000080, HD34136, HD27869, HD40545, HD36801] and does not necessarily represent the official views of the NICHD or NIH.

The authors thank the following subcommittee members who participated in protocol development and coordination between clinical research centers (Karen Dorman, R.N., M.S.), protocol/data management and statistical analysis (Julia Zachary and Yuan Zhao, M.S.), and protocol development and oversight (Catherine Y. Spong, M.D.).

\section{REFERENCES}

1. Meis PJ, Klebanoff M, Thom E, et al. Prevention of recurrent preterm delivery by 17 alphahydroxyprogesterone caproate. N Engl J Med. 2003; 348:2379-85. [PubMed: 12802023] N Engl J Med. 2003; 349:1299. Erratum in:

2. American College of Obstetricians and Gynecologists. ACOG committee opinion no 419: use of progesterone to reduce preterm birth. Obstet Gynecol. 2008; 112:963-5. [PubMed: 18827143]

3. [Accessed 4/26/2013] www.fda.gov/downloads/Drugs/GuidanceComplianceRegulatoryInformation/ Guidanc es/ucm072109.pdf

4. [Accessed 4/26/2013] http://www.fda.gov/downloads/Drugs/

GuidanceComplianceRegulatoryInformation/G uidances/ucm073115.pdf 
5. Johnson JW, Austin KL, Jones GS, Davis GH, King TM. Efficacy of 17a-hydroxyprogesterone caproate in the prevention of premature labor. N. Engl J Med. 1975; 293:675-690. [PubMed: 1099445]

6. Yemini M, Borenstein R, Dreazen E, Apelman Z, Mogilner BM, Kessler I, Lancet M. Prevention of premature labor by 17a-hydroxyprogesterone caproate. Am J Obstet Gynecol. 1985; 151:574-577. [PubMed: 3976757]

7. Hartikainen-Sorri AL, Kauppila A, Tuimala R. Inefficacy of 17a-hydroxyprogesterone caproate in the prevention of prematurity in twin pregnancy. Obstet Gynecol. 1980; 56:692-695. [PubMed: 7443111]

8. Keirse MJNC. Progestogen administration in pregnancy may prevent preterm delivery. Brit J Obstet Gynecol. Feb.1990 Vol. 97:149-154.

9. Grasmader K, Verwohlt PL, Kuhn KU, Frahnert C, Hiemke C, Dragicevic A, von Widdern O, Zobel A, Maier W, Rao ML. Relationship between Mirtazapine dose, plasma concentration, response and side effects in clinical practice. Pharmacopsychiatry. 2005; 38(3):113-117. Doi: 10.1055/ s-2005-864120. [PubMed: 15902580]

10. Janicak PG, Davis JM. Antipsychotic dosing strategies in acute schizophrenia. Intl Clin Psychopharm. 1996; 11(suppl 2):35-40.

11. Gugler R, Fuchs G, Dieckmann M, Somogyi A. Cimetidine plasma concentration-response relationships. Clin Pharm Thera. 1981; 29(6):744-8.

12. Caritis SN, Simhan HN, Zhao Y, Rouse DJ, Peaceman, et al. Relationship between 17hydroxyprogesterone caproate concentrations and gestational age at delivery in twin gestation. Am J Obstet Gynecol. 2012; 207:396.e1-8. [PubMed: 22959763]

13. Zhang S, Mada SR, Sharma S, Torch M, Mattison D, Caritis SN, Venkataramanan R. Simultaneous quantitation of 17a-hydroxyprogesterone in human plasma using high-performance liquid chromatography-mass spectrometry (HPLC-MS/MS). J Pharamaceutical Biomed Analy. 2008; 48:1174-1180.

14. Caritis SN, Sharma S, Venkataramanan R, Hankins G, Miodovnik M, et al. Pharmacology and placental transport of 17-hydroxyprogesterone caproate in a singleton gestation. Am J Obstet Gynecol. 2012; 207:398.e1-8. [PubMed: 22967833]

15. Caritis SN, Sharma S, Venkataramanan R, Rouse DJ, Peaceman Alan, et al. Pharmacokinetics of 17-hydroxyprogesterone caproate in multifetal gestation. Am J Obstet Gynecol. 2011; 205:40.e18. [PubMed: 21620357]

16. Cuppett C, Zhao Y, Caritis SN, Zhang S, Zhao W, Venkataramanan R. Effect of endogenous steroid hormones on 17-alpha-hydroxyprogesterone caproate metabolism. Am J Obstet Gynecol. 2013; 208:86.e1-6. [PubMed: 23063018]

17. Zhao, Y.; Cuppett, C.; Caritis, S.; Venkataramanan, R. Effect of prescription medications on 17alpha-hydroxyprogesterone caproate (17-OHPC) metabolism. Oral Presentation at the Society for Maternal-Fetal Medicine 32nd Annual Meeting; Dallas, TX. February 2012; abstract \# 14

18. Senat M-V, Porcher R, Winer N, et al. Prevention of preterm delivery by 17 alphahydroxyprogesterone caproate in asymptomatic twin pregnancies with a short cervix: a randomized controlled trial. Am J Obstet Gynecol. 2013; 208:194.e1-8. [PubMed: 23433324]

19. Grobman WA, Thom EA, Spong CA, Iams JD, Saade GR, et al. 17 alpha-hydroxyprogesterone caproate to prevent prematurity in nulliparas with cervical length less than $30 \mathrm{~mm}$. Am J Obstet Gynecol. 2012; 207:390.e1-8. [PubMed: 23010094]

20. Durnwald CP, Lynch CD, Walker H, et al. The effect of treatment with 17 alphahydroxyprogesterone caproate on changes in cervical length over time. Am J Obstet Gynecol. 2009; 201:410.e1-5. [PubMed: 19716117]

21. Facchinetti F, Paganelli S, Comitini G, Dante G, Volpe A. Cervical length changes during preterm cervical ripening: effects of 17-a-hydroxyprogesterone caproate. Am J Obstet Gynecol. 2007; 196:453.e1-453.e4. [PubMed: 17466698] 
Condensation: Low 17-OHPC plasma concentration is associated with an increased risk of spontaneous preterm birth. 


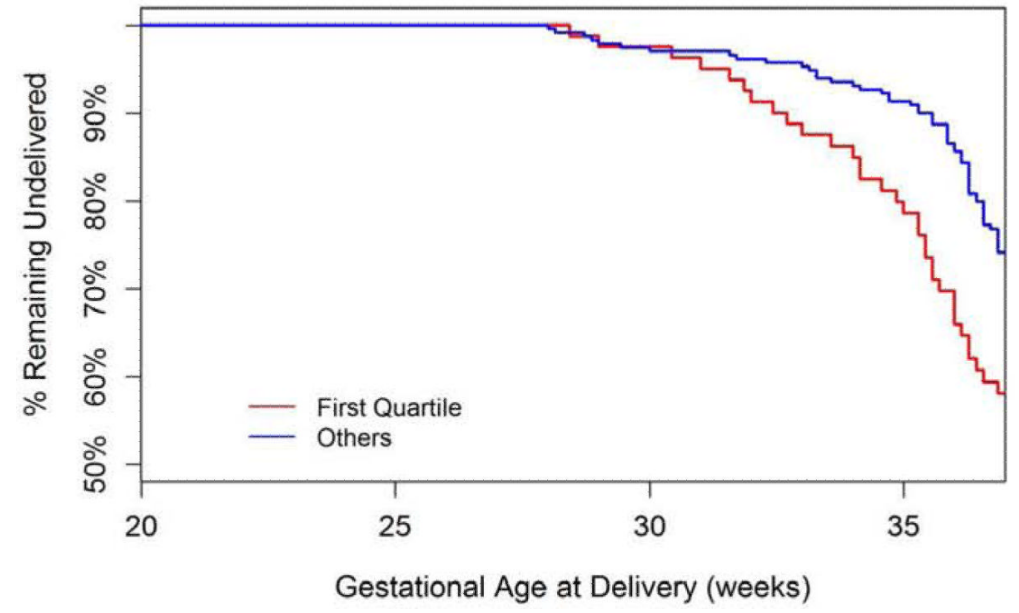

Figure 1.

The data reflect the estimated distributions of gestational age at delivery for subjects with plasma 17-OHPC concentrations in the first quartile vs quartiles 2-4 combined. 


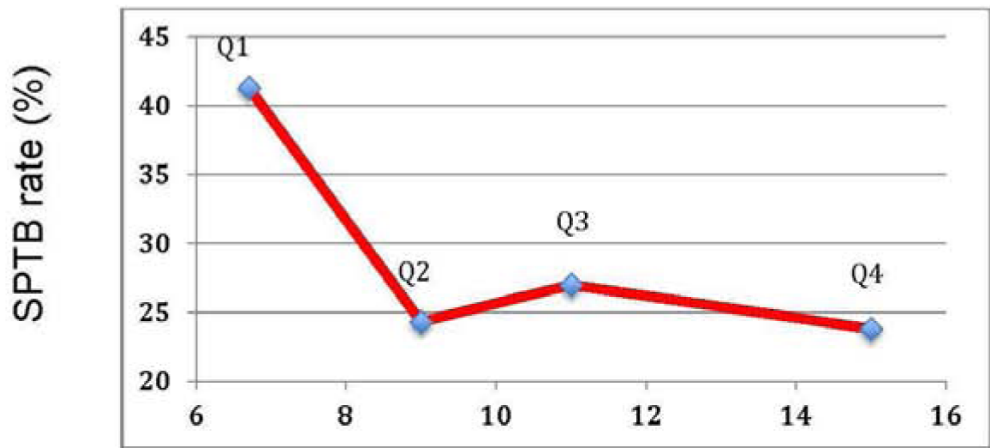

17-OHPC concentration ( $\mathrm{ng} / \mathrm{ml})$

Figure 2.

Relationship between median 17-OHPC concentration from each quartile (Q1-Q4) of 17$\mathrm{OPHC}$ concentrations and the rate of spontaneous preterm birth for each of those quartiles. 
Table 1

Demographic Characteristics of Population

\begin{tabular}{|l|c|c|c|}
\hline & Omega-3 & Placebo & p value \\
\hline Cases & 162 & 153 & \\
\hline BMI, mean (SD) & $26.0(6.1)$ & $26.1(6.9)$ & 0.81 \\
\hline Race, N(\%) & & & 0.89 \\
\hline African American & $43(26.5 \%)$ & $44(28.8 \%)$ & \\
\hline Hispanic & $24(14.8 \%)$ & $21(13.7 \%)$ & \\
\hline Caucasian & $95(58.6 \%)$ & $88(57.5 \%)$ & \\
\hline GA (weeks) @ sample time, mean (SD) & $27.0(1.4)$ & $26.9(1.5)$ & 0.25 \\
\hline GA (weeks) @ delivery, mean (SD) & $37.4(2.3)$ & $37.0(3.0)$ & 0.76 \\
\hline Progesterone (ng/ml), mean (SD) & $72.4(26.9)$ & $70.5(22.1)$ & 0.63 \\
\hline 17-OHPC (ng/ml), mean (SD) & $11.3(5.8)$ & $10.7(4.0)$ & 0.79 \\
\hline $\begin{array}{l}\text { \# of injections at time of blood sample, } \\
\text { median (interquartile range) }\end{array}$ & $9(7-10)$ & $9(7-10)$ & 0.26 \\
\hline Delivery < 37 0/7 weeks & $53(32.7 \%)$ & $53(34.6 \%)$ & 0.72 \\
\hline
\end{tabular}




\begin{tabular}{|c|c|c|c|c|c|c|c|}
\hline \multirow[b]{2}{*}{$\begin{array}{l}N \\
\frac{0}{0} \\
\frac{\pi}{\sigma}\end{array}$} & \multirow{2}{*}{ 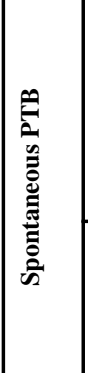 } & $\begin{array}{l}0 \\
0 \\
0 \\
0 \\
0 \\
0\end{array}$ & & $\begin{array}{l}\widehat{\sigma} \\
\hat{\sigma} \\
1 \\
1 \\
\tilde{1} \\
0 \\
0 \\
0 \\
0 \\
0\end{array}$ & \begin{tabular}{|c|}
$\hat{\sigma}$ \\
$\stackrel{0}{1}$ \\
1 \\
$\hat{n}$ \\
$e$ \\
$\tilde{n}$ \\
$\hat{n}$ \\
0
\end{tabular} & 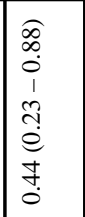 & \\
\hline & & 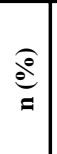 & 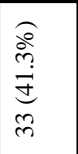 & 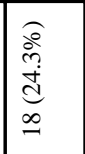 & 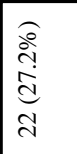 & 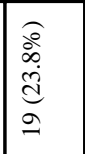 & $\cong$ \\
\hline \multirow{5}{*}{ 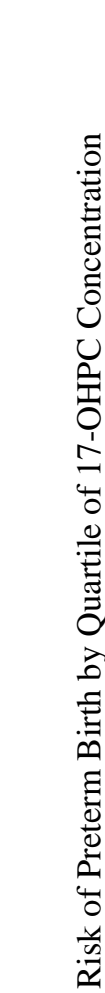 } & \multirow[t]{2}{*}{ 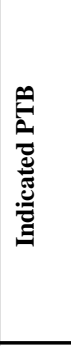 } & $\begin{array}{l}0 \\
0 \\
8 \\
\hat{0} \\
0 \\
0\end{array}$ & & 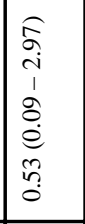 & $\begin{array}{l}\hat{D} \\
\hat{i} \\
i \\
1 \\
o \\
e \\
e \\
o \\
o \\
0 \\
\end{array}$ & 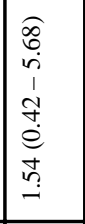 & \\
\hline & & $\begin{array}{l}\stackrel{0}{O} \\
=\end{array}$ & 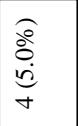 & 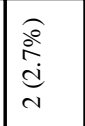 & 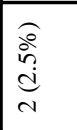 & 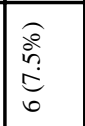 & 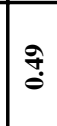 \\
\hline & \multirow[t]{2}{*}{$\stackrel{\vartheta}{\hat{E}}$} & $\mid$\begin{tabular}{|c|}
0 \\
0 \\
0 \\
6 \\
$\approx$ \\
0 \\
0
\end{tabular} & & 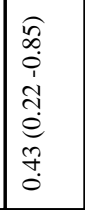 & 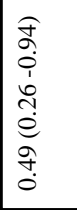 & 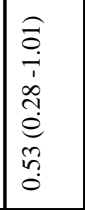 & \\
\hline & & 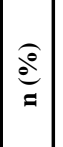 & 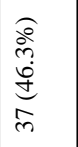 & 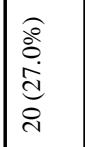 & 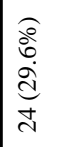 & 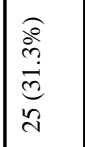 & 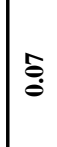 \\
\hline & 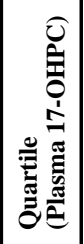 & & 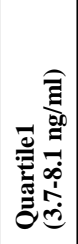 & 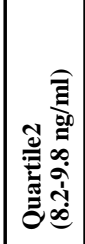 & 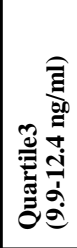 & 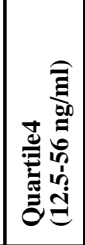 & 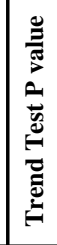 \\
\hline
\end{tabular}

Am J Obstet Gynecol. Author manuscript; available in PMC 2015 February 01. 